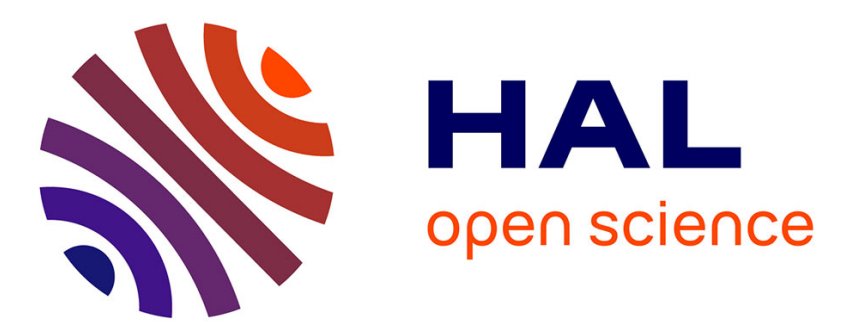

\title{
Control of melt decomposition for the growth of high quality AgGaGeS 4 single crystals for mid-IR laser applications
}

\author{
J. Rame, J Petit, B Viana, J.M. Melkonian, Q Clement
}

\section{- To cite this version:}

J. Rame, J Petit, B Viana, J.M. Melkonian, Q Clement. Control of melt decomposition for the growth of high quality AgGaGeS 4 single crystals for mid-IR laser applications. Crystal Growth \& Design, 2014, 18 p. 10.1021/cg500813q · hal-01080270

\section{HAL Id: hal-01080270 https://hal.science/hal-01080270}

Submitted on 6 Nov 2014

HAL is a multi-disciplinary open access archive for the deposit and dissemination of scientific research documents, whether they are published or not. The documents may come from teaching and research institutions in France or abroad, or from public or private research centers.
L'archive ouverte pluridisciplinaire HAL, est destinée au dépôt et à la diffusion de documents scientifiques de niveau recherche, publiés ou non, émanant des établissements d'enseignement et de recherche français ou étrangers, des laboratoires publics ou privés. 


\title{
Control of melt decomposition for the growth of high quality $\mathrm{AgGaGeS}_{4}$ single crystals for mid-IR laser applications
}

\author{
J. Rame, ${ }^{\dagger}$ J. Petit, ${ }^{*}{ }^{\dagger}$ B. Viana, ${ }^{\ddagger}$ J.M. Melkonian, ${ }^{\dagger}$ and Q. Clement ${ }^{\dagger}$ \\ ONERA The French Aerospace Lab, 92320 Chatillon, France, and IRCP Chimie \\ ParisTech, 11 rue Pierre et Marie Curie, 75231 Paris Cedex 05, France \\ E-mail: johan.petit@onera.fr
}

\begin{abstract}
$\mathrm{AgGaGeS}_{4}$ (AGGS) is a promising nonlinear crystal for mid-IR laser applications which could fulfill the lack of material able to convert a $1.064 \mu \mathrm{m}$ pump signal (Nd:YAG laser) into wavelengths higher than $4 \mu \mathrm{m}$ up to $11 \mu \mathrm{m}$. The processing steps of this material are presented in this study. The key issue of AGGS crystal processing is the control of decomposition at high temperature due to the high volatility of $\mathrm{GeS}_{2}$. This study present the solutions to obtain high quality single crystal. AGGS crystals with 28 $\mathrm{mm}$ diameter and $70 \mathrm{~mm}$ length were grown by the Bridgman-Stockbarger method. The crystals have good homogeneity and high transparency in the $0.5-11.5 \mu \mathrm{m}$ spectral range making it suitable for optical experiments. The influence of $\mathrm{GeS}_{2}$ volatility on melt stoichiometry during the $\mathrm{AgGaGeS}_{4}$ processing is outlined and solutions to improve the crystals quality are presented.
\end{abstract}

\footnotetext{
${ }^{*}$ To whom correspondence should be addressed

$\dagger$ ONERA

†IRCP
} 


\section{Introduction}

Mid-infrared laser sources have attracted a particular attention due to their potential applications in different fields such as infrared counter-measures and remote chemical sensing. ${ }^{1}$ One way to produce such sources is the down conversion process in optical parametric oscillators based on birefringence phase-matching in non linear crystals. However, there is a lack of materials able to convert directly a high energy pump signal, from a $1.064 \mu \mathrm{m}$ Nd:YAG laser for example, to wavelengths higher than $4 \mu \mathrm{m}$. Thus, the large majority of the infrared sources based on the OPO technology are complex and bulky systems such as tandem OPO schemes where a first OPO is used to pump the mid-IR OPO(REF). Consequently, it would be interesting to convert efficiently a commercial Nd:YAG source, with good beam quality and high power, to develop compact and tunable high power mid-IR sources. Thus, the development of such systems required the use of materials able to convert efficiently a $1.064 \mu \mathrm{m}$ source and that's the reason why we have been particularly interested in $\mathrm{AgGaGeS}_{4}$. Indeed, this material has a wide transmission range $(0.5-11.5 \mu \mathrm{m})$ and an absorption coefficient as low as $0.05 \mathrm{~cm}^{-1}$ at $1.064 \mu \mathrm{m}$ making it compatible with a Nd:YAG laser pump. ${ }^{2} \mathrm{AgGaGeS}_{4}$ has an orthorhombic mm2 symmetry and belongs to the $\mathrm{C}_{2 v}^{19}$-Fdd2 space group. ${ }^{3}$ This material demonstrated a high laser damage threshold, with $50 \mathrm{MW} / \mathrm{cm}^{2}$ at $1.064 \mu \mathrm{m}(\tau=10 \mathrm{~ns}),{ }^{4} 1.1 \mathrm{~J} / \mathrm{cm}^{2}\left(73 \mathrm{MW} / \mathrm{cm}^{2}\right)$ at $2.05 \mu \mathrm{m}(\tau=15 \mathrm{~ns} ; 10 \mathrm{kHz})^{2}$ and $230 \mathrm{MW} / \mathrm{cm}^{2}(\tau=30 \mathrm{~ns})$ at $9.55 \mu \mathrm{m},{ }^{5}$ which makes this material promising for high power applications. The nonlinear optical properties of AGGS were first reported by Petrov et $\mathrm{al}^{6}$ in 2004. Then, several teams have reported encouraging results concerning the utilisation of AGGS in frequency mixing processes such as Second Harmonic Generation (SHG) or Difference Frequency Generation (DFG). ${ }^{7}$ However, difficulties relatives to the growth of good optical quality AGGS single crystals where pointed out ${ }^{8}$ and dissimilar results were reported regarding the phase stability of the $\mathrm{AgGaS}_{2}-\mathrm{GeS}_{2}$ system. Indeed, Badikov et al. ${ }^{4}$ indicated that AGGS has a stability range included between 46 and 83 mol. $\%$ of GeS $_{2}$ with a $845^{\circ} \mathrm{C}$ congruent melting point. On the contrary, Chbani et $\mathrm{al}^{9}$ reported that AGGS phase 
has a fixed composition and an incongruent melting point at $840^{\circ} \mathrm{C}$. Lastly, Olekseyuk et al. ${ }^{10}$ indicated that AGGS phase, with variable compositions, exists in the $48-55 \mathrm{~mol} \% \mathrm{GeS}_{2}$ and they assumed that previous published results were incorrect due to the measurements performed on non equilibrated alloys. These contradictory results are due to the volatility of AGGS derivatives compounds and particularly to the germanium sulfide $\left(\mathrm{GeS}_{2}\right)$ vaporization which can induce stoichiometry deviation from the melt. Thus, the control of AGGS processing steps, taking into account the vaporization of $\mathrm{GeS}_{2}$, appears to be a key issue for the growth of good optical quality AGGS single crystals. Thus, after presenting the experimental conditions to obtain high quality AGGS single crystals, we are going to discuss all the steps explaining the impact of the volatile compounds on the crystal growth and the optimization of the processing steps.

\section{Experimental section}

\section{Chemical synthesis of $\mathrm{AgGaGeS}_{4}$}

$\mathrm{AgGaGeS}_{4}$ polycrystals were synthesized from high purity elements Ag, Ga, Ge and S (5 or $6 \mathrm{~N})$. A stoichiometric amount of the starting elements, for a total of $110 \mathrm{~g}$, was introduced in a quartz ampoule under argon atmosphere. The quartz reactor was evacuated to $10^{-4}$ mbar and sealed. The ampoule was placed into the synthesis furnace, tilted by $15^{\circ}$ relative to the horizontal, which is confined into a stainless steal autoclave. The synthesis process was carried out using the two zone temperature method. This method allows to make the reaction between the different components at high temperature while limiting the explosion hazards related to the high vapour pressure of sulphur components. The thermal profile of the oven during the synthesis steps was simulated by finite elements and is shown on Figure 1. In the first step (Figure 1-a), temperature was raised to $950^{\circ} \mathrm{C}$ in the lower zone where the heterogeneous chemical reaction takes place between liquids (Ag, Ga, Ge, GeS 2 ) and gas $\left(\mathrm{S}, \mathrm{GeS}_{2}\right)$ components. Volatile compounds are condensed in the upper zone, whose 


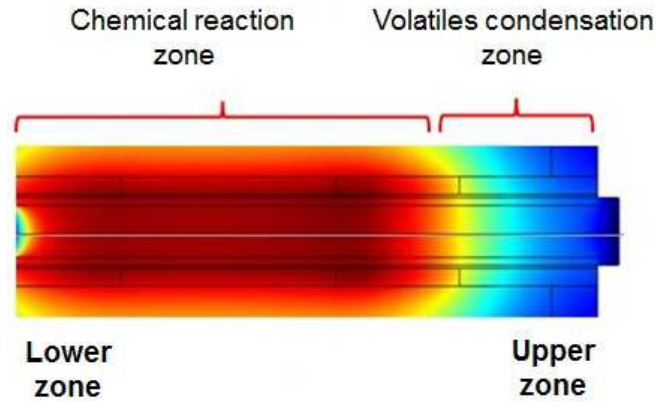

a

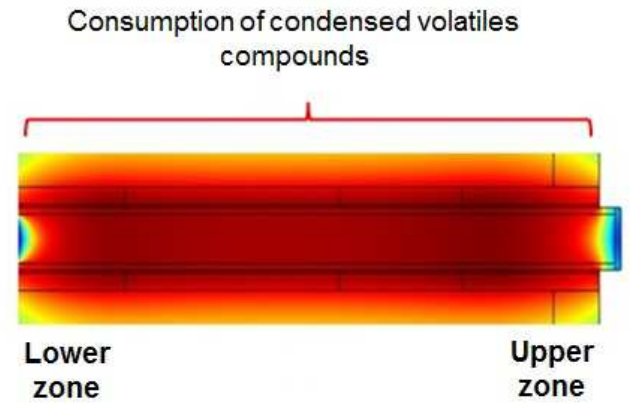

b

Figure 1: Simulation of oven thermal profile in the first (a) and second (b) steps of the chemical synthesis process.

temperature is around $450^{\circ} \mathrm{C}$. This reduces the rising pressure. Once the major part of volatile have reacted, the temperature was slowly raised in the upper zone, up to $1000^{\circ} \mathrm{C}$, in order to consume the remaining condensed sulphide compounds (Figure 1-b). After a 12h homogenisation step, the entire ampoule was cooled down to $500^{\circ} \mathrm{C}$ at $0.2^{\circ} \mathrm{C} \cdot \mathrm{min}^{-1}$ and then at room temperature at $5^{\circ} \mathrm{C} \cdot \mathrm{min}^{-1}$. Polycrystalline ingot, visible on Figure 2, was collected breaking the quartz ampoule.

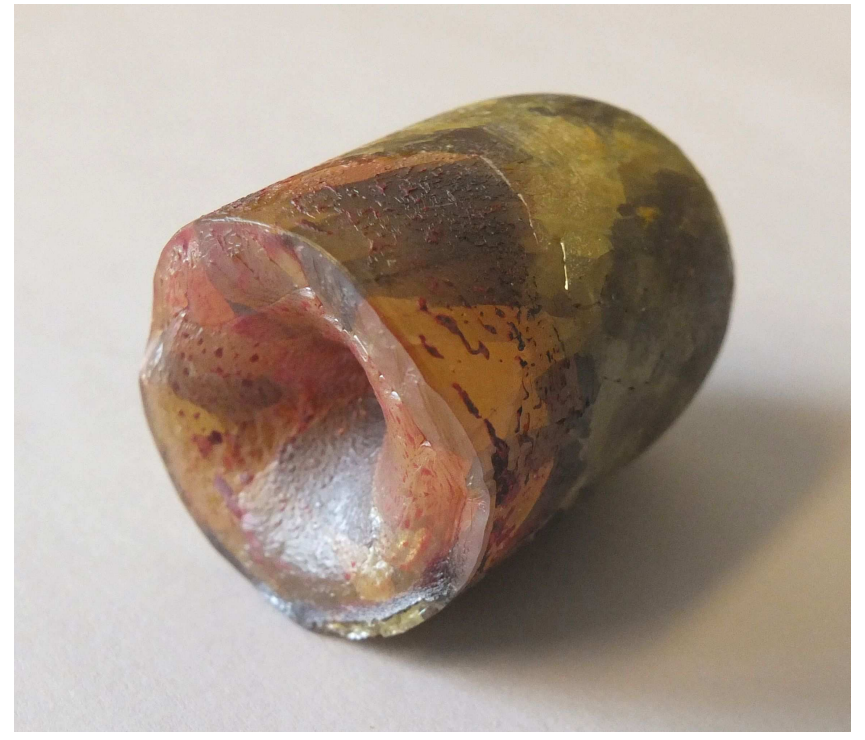

Figure 2: $\mathrm{AgGaGeS}_{4}$ polycrystalline ingot after the first step : chemical synthesis. 


\section{Single crystal growth of $\mathrm{AgGaGeS}_{4}$}

The crystal growth was performed from previously synthesized AGGS polycrystals. A single crystal seed, extracted from a large grain of the same polycrystal, was placed at the bottom of a specially designed quartz growth ampoule (Figure 3(a)). The AGGS polycrystals were

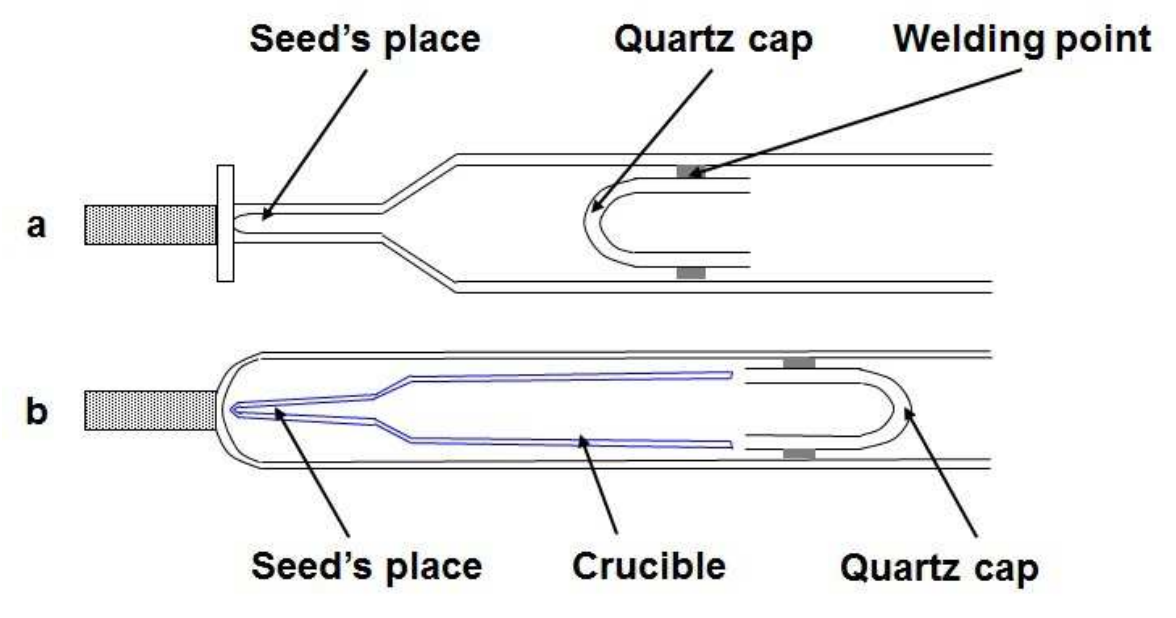

Figure 3: Schemes of quartz ampoules designed for growing crystal from seed without (a) and with (b) crucible.

ground into powder and introduced above the single crystal seed. A quartz cap was used in order to reduce, as much as possible, the free volume above the grounded sample. The ampoule was evacuated to $10^{-4}$ mbar for $1 \mathrm{~h}$, sealed and loaded into the furnace. The single crystal growth was performed using the Bridgman-Stockbarger method. The BridgmanStockbarger oven is a vertical tube furnace (Cyberstar Inc.). Temperatures of each zone were increased at the rate of $30^{\circ} \mathrm{C} \cdot \mathrm{h}^{-1}$. The upper zone was raised to $895^{\circ} \mathrm{C}$ and the lower one to $835{ }^{\circ} \mathrm{C}$ leading to a temperature gradient of $12^{\circ} \mathrm{C}_{\mathrm{cm}} \mathrm{cm}^{-1}$ at the $845^{\circ} \mathrm{Cmelting}$ point. At the beginning, the ampoule was positioned to start the crystallisation from the seed. After a $5 \mathrm{~h}$ homogenization step, the ampoule was pulled down at a rate of $0.4 \mathrm{~mm} \cdot \mathrm{h}^{-1}$. At the end, the temperature of the furnace was cooled at $10^{\circ} \mathrm{C} \cdot \mathrm{h}^{-1}$ down to $785^{\circ} \mathrm{C} \cdot \mathrm{h}^{-1}$ and then at $30^{\circ} \mathrm{C} \cdot \mathrm{h}^{-1}$ down to room temperature. The as-grown single crystal, orange in color, was $28 \mathrm{~mm}$ in diameter and $70 \mathrm{~mm}$ in length. The crystal was translucent with the presence of 
inhomogeneity of refraction index and inclusions. A sample cut from single crystal is shown on Figure 4(a).

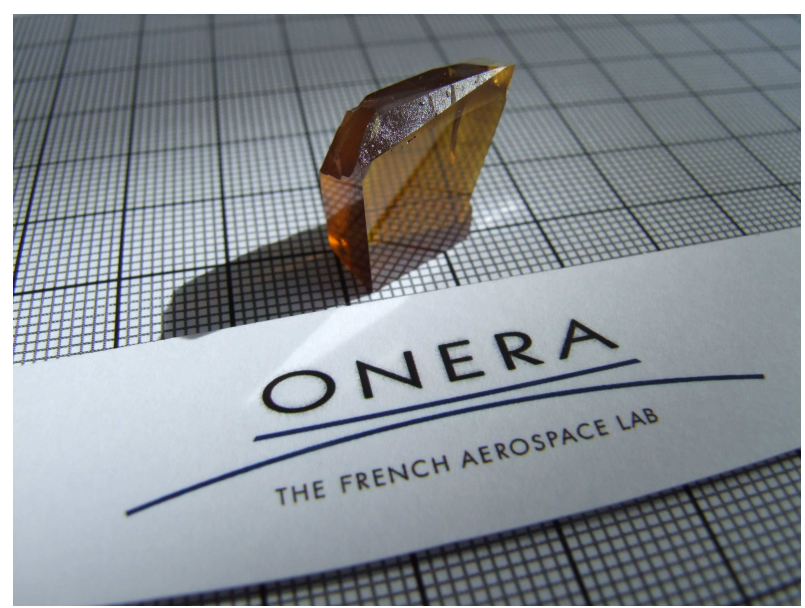

(a)

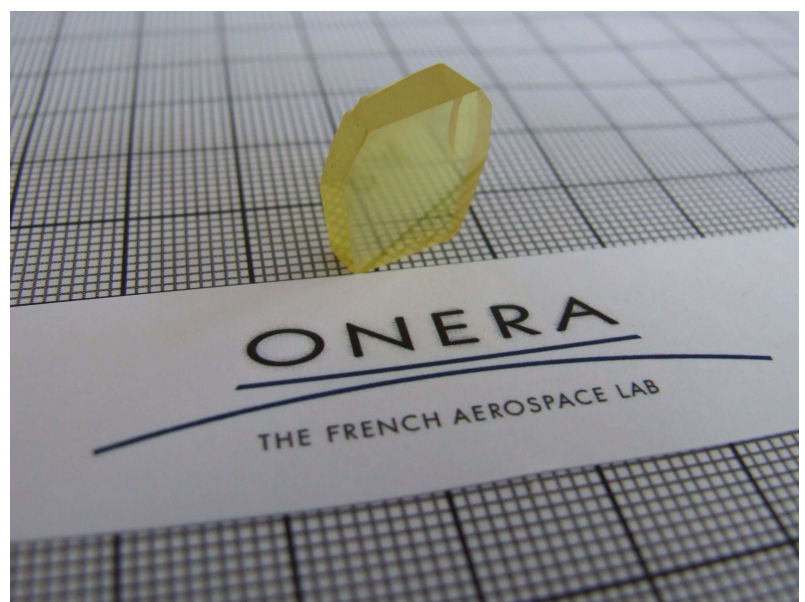

(b)

Figure 4: Picture of a cut and polished $\mathrm{AgGaGeS}_{4}$ single crystal before (a) and after posttreatment (b).

\section{Post-growth treatments}

A post-growth treatment step was performed in order to increase the quality of as-grown crystal. Thermal annealing was performed using the apparatus previously described. ${ }^{11}$ The samples were introduced into a quartz ampoule which was evacuated and capped using a ground glass stopper. The annealing was performed under static vacuum at $600^{\circ} \mathrm{C}$ for 250 h. After this step, the samples were translucent and yellow in color (Figure 4(b)) with no presence of defects visible to the naked eye.

\section{Characterizations}

X-ray powder diffraction was performed using a Panalytical X'Pert Pro diffractometer operating at $\mathrm{Cu} \mathrm{K}_{\alpha}(1.54182 \AA)$ wavelength and equipped with a front beam Ge (1 111$)$ monochromator and a linear PixCell detector. The samples were ground to powder before measurement 
and the pattern were collected at room temperature in the $2 \theta$ range of $10-80^{\circ}$ with a $0.05^{\circ} . s^{-1}$ scanning rate.

Samples composition and microstructure were determined using a ZEISS DSM962 Scanning Electron Microscope (SEM) and Energy dispersive X-ray spectroscopy (EDS) was performed at $15 \mathrm{kV}$ without reference samples.

Differential thermal analysis (DTA) measurement were carried out using a Setsys evolution 16/18 (SETARAM Inc.) Differential Thermal Analyzer. Pure silver, aluminium and copper where used for the DTA temperature calibration. Then, about $100 \mathrm{mg}$ of samples were introduced into small quartz crucibles which were evacuated and sealed. These sealed crucibles avoid the vaporisation losses of volatile compounds during the experiments.

The optical properties were studied using a Nicolet 5700 FT-IR spectrometer in the 1,6$14 \mu \mathrm{m}$ range and a cary 6000 (Varian) spectrometer for the visible and near-infrared range (0,4-1,7 $\mu \mathrm{m})$. The samples were polished before measurements. Absorption coefficients were calculated referring to the Sellmeier coefficients provided by Das et al. ${ }^{12}$

The conductivity measurements were performed using a XX conductimeter. The Measures were performed at room temperature on polished samples without any coating.

Study of $\mathrm{GeS}_{2}$ vapor pressure variation over the $\mathrm{AgGaGeS}_{4}$ melt was simulated using the HSC Chemistry software.

\section{Results and discussion}

\section{Chemical synthesis}

$\mathrm{AgGaGeS}_{4}$ phase is formed in the solid solution $\mathrm{AgGaS}_{2}-\mathrm{GeS}_{2}$. This compound has a narrow stability range included between 48 and $55 \mathrm{GeS}_{2}$ mol\% compositions according to the last published phase diagram ${ }^{10}$ to which we will refer in the discussion. Indeed, a composition below $48 \% \mathrm{GeS}_{2}$ mol\% and above $55 \% \mathrm{GeS}_{2}$ mol\% lead to the formation of the mixed $\mathrm{AgGaGeS}_{4}+\mathrm{AgGaS}_{2}$ and $\mathrm{AgGaGeS}_{4}+\mathrm{GeS}_{2}$ phases respectively. Otherwise, AGGS de- 


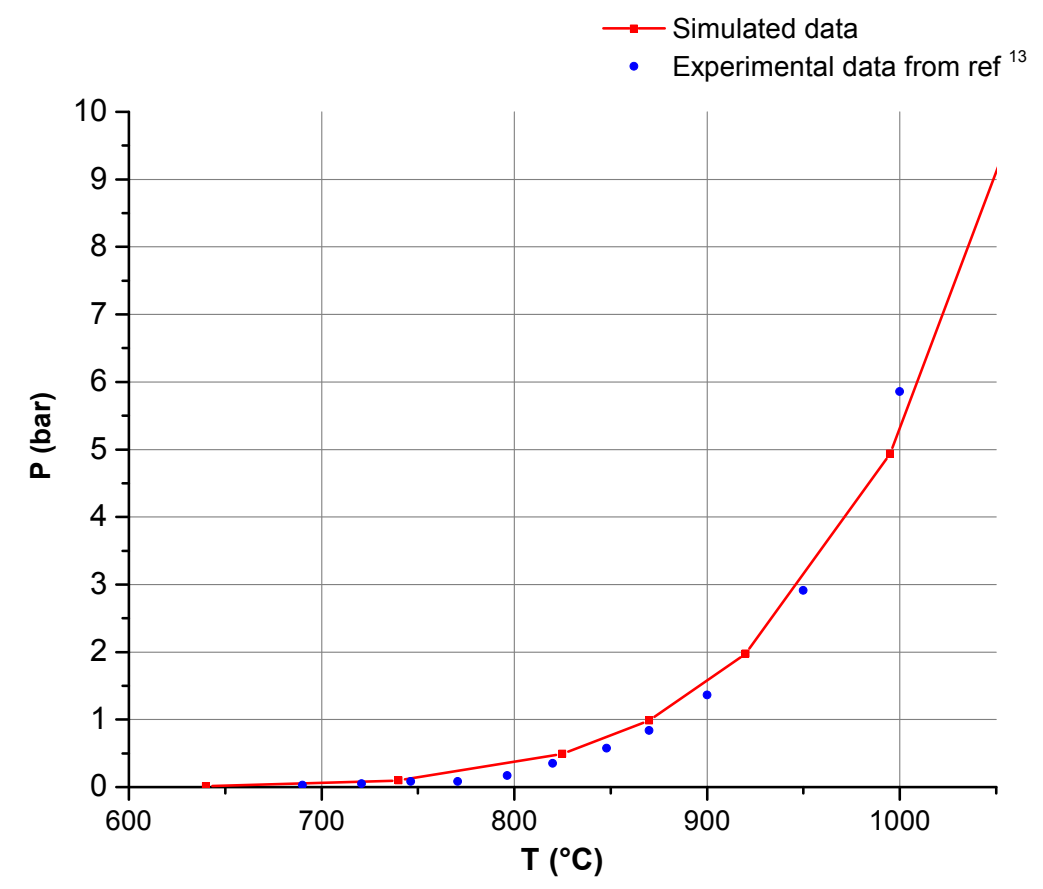

Figure 5: Plot of simulated $\mathrm{GeS}_{2}$ vapor pressure variation (red line) versus temperature and comparison with experimental data from ref. ${ }^{13}$

composes at high temperature to form $\mathrm{AgGaS}_{2}$ and $\mathrm{GeS}_{2}$ phases according to the reaction: ${ }^{13}$

$$
A g G a G e S_{4 S(L)} \rightleftharpoons A g G a S_{2 S(L)}+G e S_{2(L)} \rightleftharpoons A g G a S_{2 S(L)}+G e S_{2(V)}
$$

Moreover, starting above $627^{\circ} \mathrm{C}, \mathrm{GeS}_{2}$ dissociates in the vapor phase to form $\mathrm{GeS}$ and $\mathrm{S}_{x}$. However, to simplify the discussion, we will refer to $\mathrm{GeS}_{2}$ rather than $\mathrm{GeS}$ and $\mathrm{S}_{x}$ species. In order to study the $\mathrm{GeS}_{2}$ vapor pressure behaviour with the increasing temperature , thermodynamic calculations were performed relatively to the second part of the previous equation. The results of the simulations are reported on Figure 5 and are compared to experimental data extrapolated from Vasil'eva et al. ${ }^{13}$ They are in good agreement with experimental results and indicated that $\mathrm{GeS}_{2}$ vapor pressure increases quickly above 700 ${ }^{\circ} \mathrm{C}$. Thus, vapor pressure of $\mathrm{GeS}_{2}$ is about 0.7 bar around the $845^{\circ} \mathrm{C}$, at the melting point temperature of $\mathrm{AgGaGeS}_{4}$ reported by Badikov et $\mathrm{al}^{4}$ and about 5 bar at $1000^{\circ} \mathrm{C}$ which is the highest chemical synthesis temperature in our process. This vaporization can induce a 
deviation from the initial composition depending on the synthesis conditions, the amount of starting elements and the reactor volume. A small deviation from stoichiometry, keeping the composition in the range of pure AGGS phase formation, can induce structural defects as germanium or sulphur vacancies in the crystal structure and so undesired optical absorptions reducing the optical quality of the crystal. However, if the $\mathrm{GeS}_{2}$ vaporization lead to a melt composition below $48 \mathrm{~mol} \% \mathrm{GeS}_{2}$, inclusions of $\mathrm{AgGaS}_{2}$ appears in the material which became opaque and inexploitable for our applications as shown on the Figure 6 . Indeed, this SEM picture of our first synthesis show a microstructure composed by a grey and a white phases identified as $\mathrm{AgGaGeS}_{4}$ and $\mathrm{AgGaS}_{2}$ according to EDS analysis. Thus, the synthesis

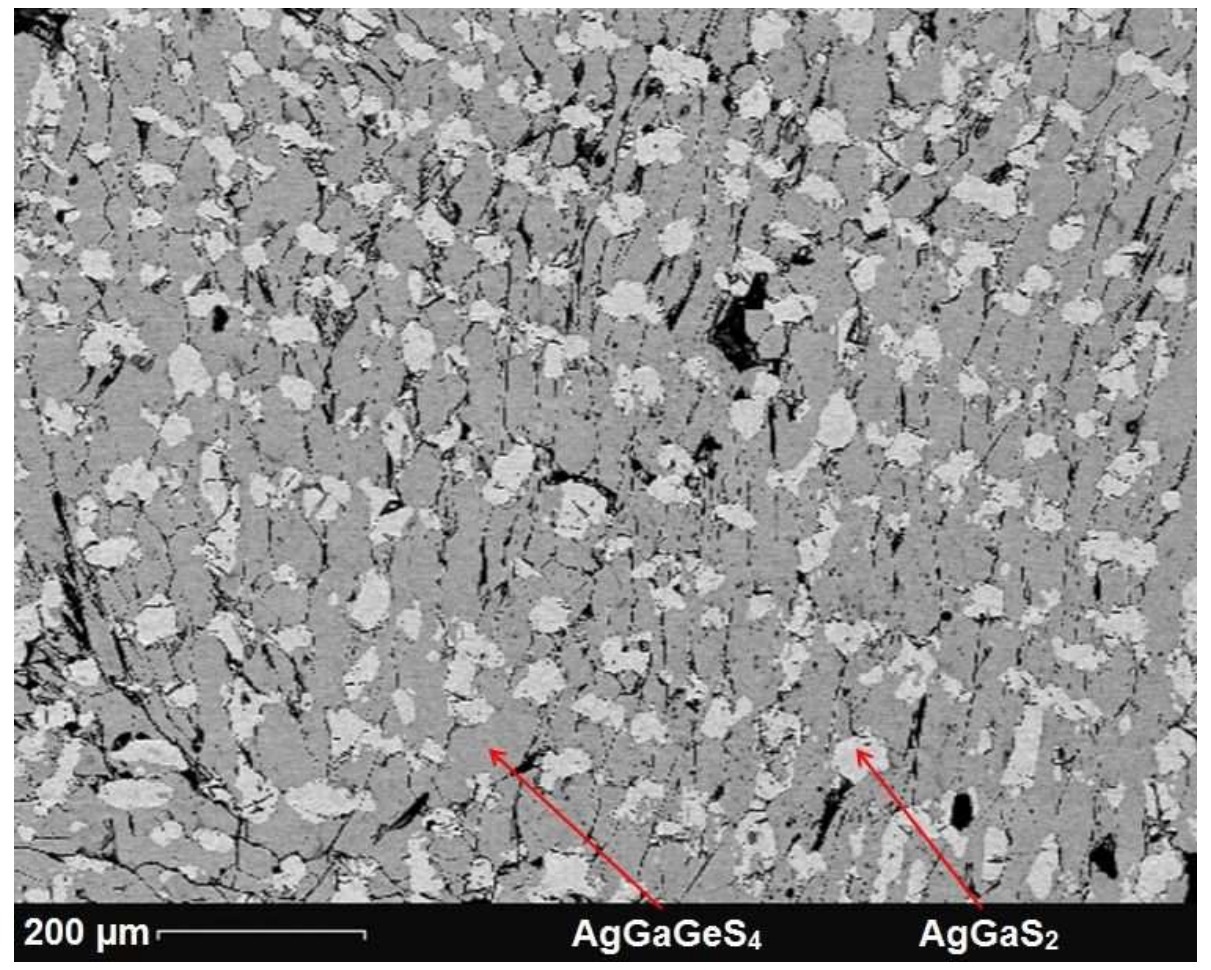

Figure 6: SEM picture of a crystal's cut showing the microstructure composed by a mixture of $\mathrm{AgGaGeS}_{4}$ and $\mathrm{AgGa}_{2}$ phases.

of pure AGGS phase is a gentle process which requires to take into account the vaporization of $\mathrm{GeS}_{2}$. Consequently, our work focused on reducing the effect of the $\mathrm{GeS}_{2}$ vaporization on melt stoichiometry in order to prepare high quality AGGS polycrystals. To do that, parameters such as ampoule volume, starting elements amounts and synthesis temperature had to be 
optimized. Firstly, in our case, as vapor pressure only depends on temperature, the ratio between the ampoule volume and the amount of starting elements can be optimized within two directions: (i) either to limit the volume of the ampoule and (ii) increase the reactants quantity. Thus, for a given ampoule volume, the more the starting elements quantity, the less the vaporization of $\mathrm{GeS}_{2}$ will affect the initial composition. Indeed, for $110 \mathrm{~g}$ of starting elements and a $190 \mathrm{~cm}^{3}$ ampoule, the calculated vapor pressure of $\mathrm{GeS}_{2}$ is 0.7 bar around $845^{\circ} \mathrm{C}$. This vapor pressure of $\mathrm{GeS}_{2}$ corresponds to $0.2 \mathrm{~g}$ of $\mathrm{GeS}_{2}$ representing $0.5 \mathrm{~mol} \%$ of the total $\mathrm{GeS}_{2}$ mass. Thus, in these conditions, the melt composition is maintained in the stability range of the $\mathrm{AgGaGeS}_{4}$ phase. ${ }^{10}$ However, if we decrease the amount of starting elements, the mass of $\mathrm{GeS}_{2}$ in the vapor phase will represent a higher ratio than previously and the melt composition can be shifted outside the stability zone of $\mathrm{AgGaGeS}_{4}$. This is one reason why large nonlinear crystals of volatile compounds usually present higher quality than smaller crystals. ${ }^{14}$ However, the ratio between the ampoule volume and the starting elements amount has to be optimized taking into account the explosions hazards related to the amount of sulphur. For the moment, we have tested $120 \mathrm{~g}$ of starting elements inside a $190 \mathrm{~cm}^{3}$ ampoule which was efficient to maintain the vaporization of $\mathrm{GeS}_{2}$ low enough to synthesized pure $\mathrm{AgGaGeS}_{4}$ phase while avoiding ampoule explosion.

Otherwise, the cooling rate is another important parameter to take into consideration during the process. Indeed, the percentage of $\mathrm{GeS}_{2}$ in the vapor phase is respectively around 2.0 and $0.5 \mathrm{~mol} \% \mathrm{GeS}_{2}$ at 950 and $845^{\circ} \mathrm{C}$. Thus, a fast cooling rate can induced an important stoichiometric deviation in the final crystal if the $\mathrm{GeS}_{2}$ vapor do not have time to react with the melt before crystallisation. Consequently, the kinetic of the reaction has an important place here. For example, our experiments carried out with a cooling rate of $5^{\circ} \mathrm{C} \cdot \mathrm{min}^{-1}$ at the end of the synthesis led to ingots composed by $\mathrm{AgGaGeS}_{4}+\mathrm{AgGaS}_{2}$ phases and unreacted $\mathrm{GeS}_{2}$ at the top of the ingot as shown on Figure 7. A cooling rate of $0.2^{\circ} \mathrm{C} \cdot \mathrm{min}^{-1}$ was sufficient to promote vapor/melt reaction during cooling and totally consume the $\mathrm{GeS}_{2}$ content in the vapor phase. The $\mathrm{GeS}_{2}$ vaporisation control during these steps allowed to 
synthesize polycristals (Figure 2) with pure AGGS orthorhombic phase (JCPDS 72-1912 ${ }^{3}$ ) according to XRD analysis (Figure 8).

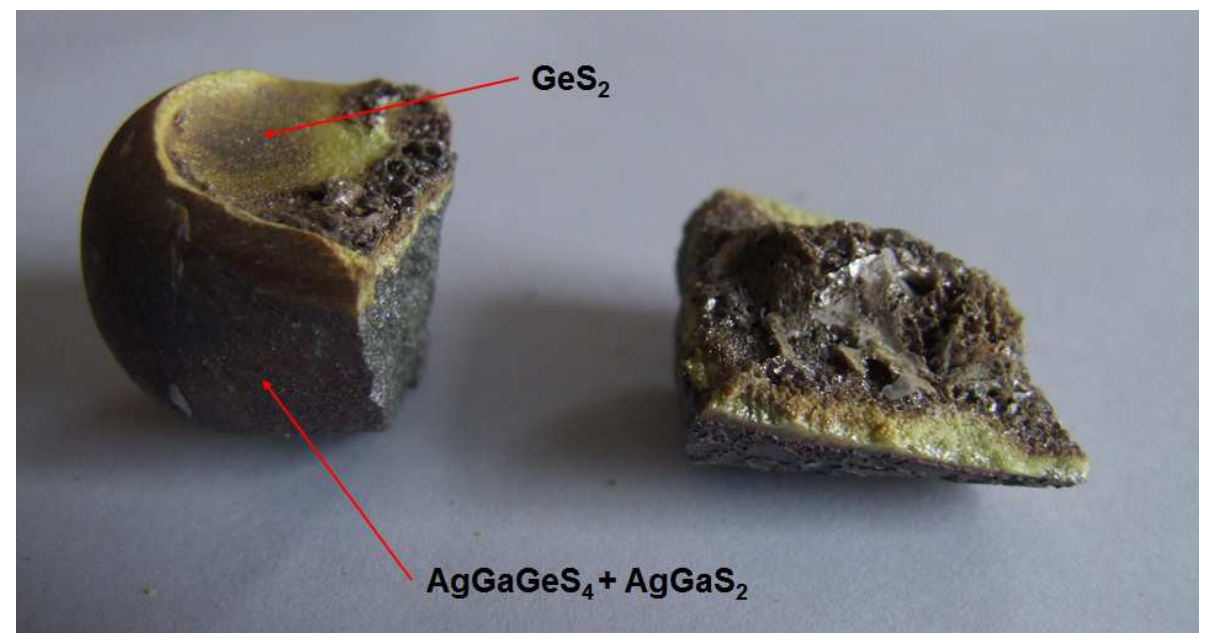

Figure 7: Picture of ingot after chemical synthesis performed with a $5^{\circ} \mathrm{C} \cdot \mathrm{min}^{-1}$ cooling rate.

\section{Crystal growth}

Vaporization of $\mathrm{GeS}_{2}$ has also a strong impact on the crystal growth step and thus on the final single crystal quality. Indeed, the ratio between starting elements and ampoule volume has also to be optimized here in order to avoid stoichiometry deviation during the crystallisation process. For example, using of special shaped ampoule (Figure 3(a)) is preferable than using a round bottom shaped ampoule and a PBN or graphite crucible (Figure 3(b)). Indeed, experiments performed with this latter led to condensation of $\mathrm{GeS}_{2}$ in the coldest part, at the ampoule bottom. This condensation occurred between the crucible and the ampoule walls which led to stoichiometry deviation in the melt and the growth of poor quality crystals. Another important parameter to take into consideration is the supercooling of AGGS. Indeed, growth from the melt without seed was performed and the results are shown in Figure 9. According to EDS analysis, the ingots grown in these conditions were all composed by a mixture of $\mathrm{AgGaGeS}_{4}$ and $\mathrm{AgGaS}_{2}$ phases in the main part and by a pure $\mathrm{AgGaGeS}$. phase at the top head of the ingot. Thus, DTA analysis were performed in order to explain 


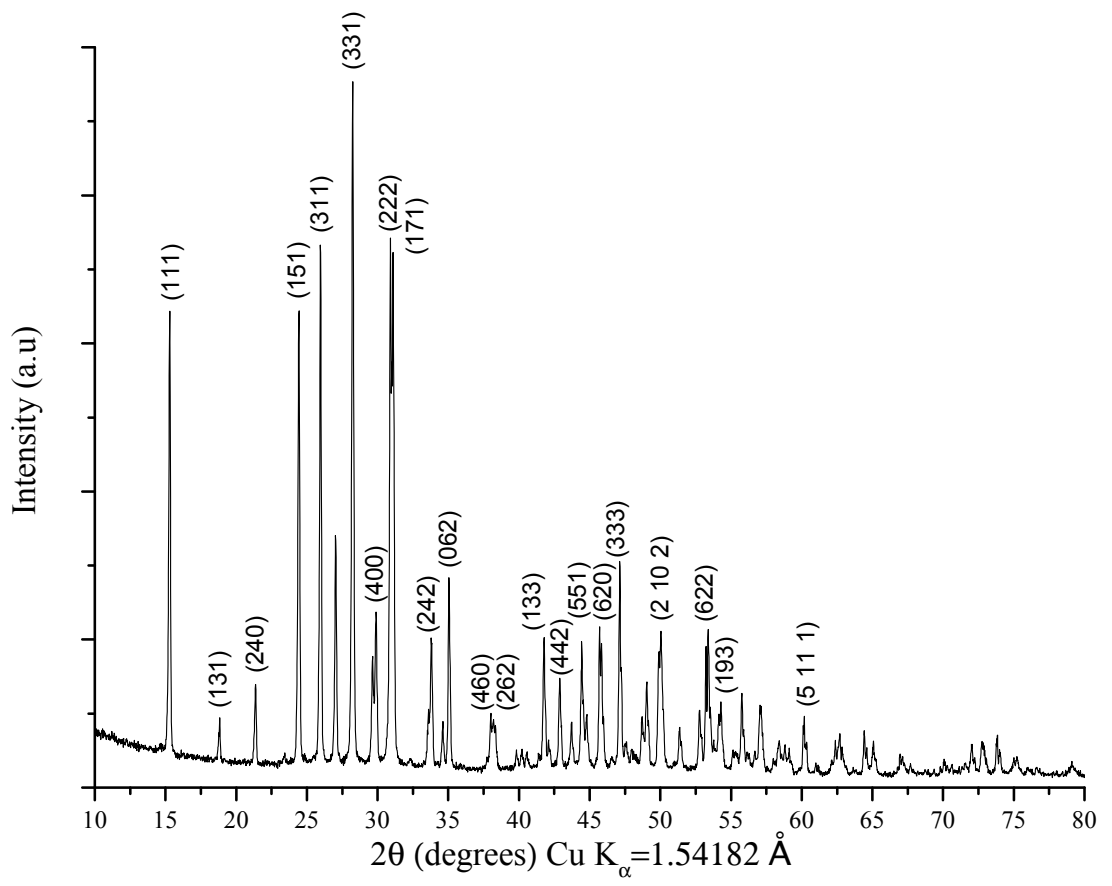

Figure 8: XRD pattern of polycristalline sample matching the $\mathrm{AgGaGeS}_{4}$ phase according to JCPDS $72-1912 .^{3}$

these results and to study the supercooling amplitude. The melting and crystallization points are respectively shown on the heating and cooling curves presented in Figure 10. The melting point, related to the endothermic peak on the heating curve, is at about $838^{\circ} \mathrm{C}$. The crystallization temperature, related to the exothermic peak on the cooling curve, is at about $752^{\circ} \mathrm{C}$. Thus, supercooling temperature value reaches $86^{\circ} \mathrm{C}$. Even if this value strongly depends on different parameters such as the container quality or the cooling rates, one can say that the supercooling is relatively high. Consequently, it should be responsible for a multi-nuclei formation observed on samples grown from the melt without seed. ${ }^{15}$ Moreover, this supercooling can induce a decomposition of the initial AGGS phase as it was recently reported by Nikolaev et al. ${ }^{16}$ The use of single crystal seed avoided the supercooling and decomposition effect by providing a starting nucleation point. This allowed to obtain AGGS single crystals whose extracted sample is shown on Figure 4(a). SEM-EDS analysis were performed on different spots of that crystal after annealing. The results indicate the good 


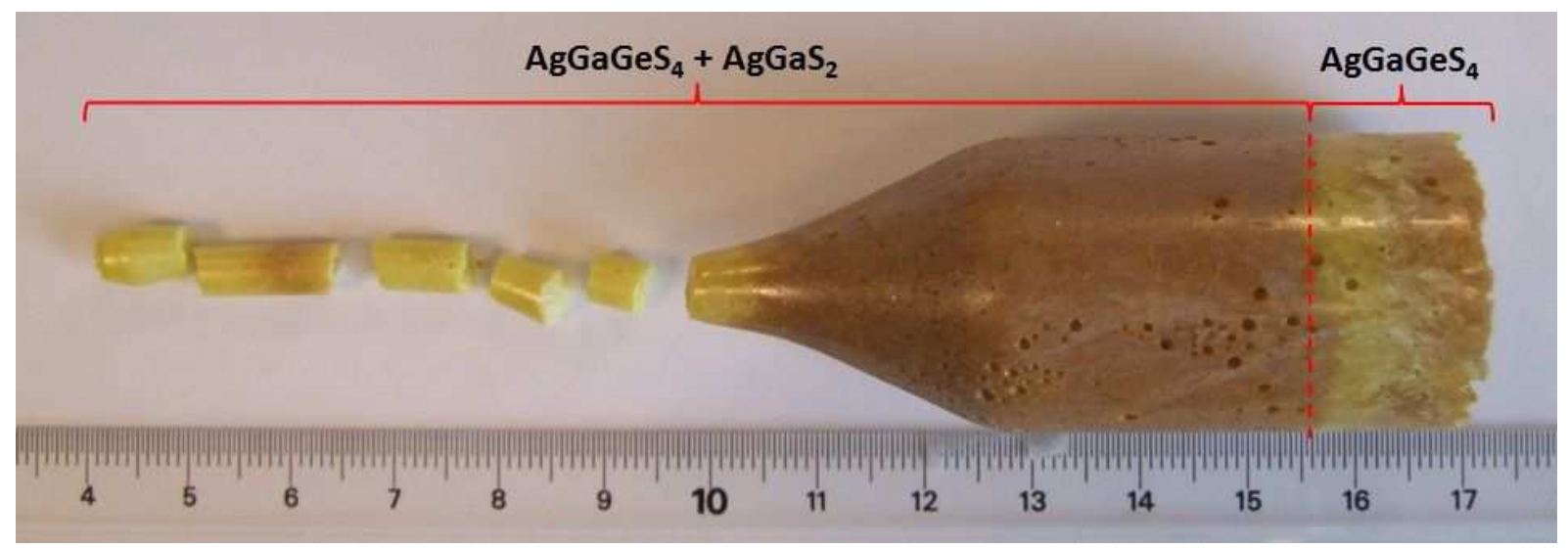

Figure 9: Picture of ingot grown from full melted polycristals without seed.

homogeneity of the single crystal with an estimated composition similar to the expected composition in the range of the $3 \%$ at precision's limit of the EDS analysis (in the previously described conditions). Optical measurements where performed on polished and annealed AGGS sample $\left(10 \times 10 \times 5 \mathrm{~mm}^{3}\right)$. The optical transmission measured at $2.05 \mu \mathrm{m}$ using a thulium doped fiber cw laser ${ }^{17}$ (20 khz, 100-400 ns, peak power $1 \mathrm{~kW}$ ) indicated an absorption coefficient of $0.04 \mathrm{~cm}^{-1}$. The absorption spectrum recorded in the $0.5-12.5 \mu \mathrm{m}$ range (Figure 11) shows that AGGS sample has high transparency from about 0.5 to $11.5 \mathrm{~cm}^{-1}$. The absorption coefficient was below $0.1 \mathrm{~cm}^{-1}$ in the $2-8 \mu \mathrm{m}$ spectral range which indicates the good optical quality of our AGGS crystal. The cut-off wavelength is $0.45 \mu \mathrm{m}$ which perfectly correspond to the $2.78 \mathrm{eV}$ band edge reported by Badikov et al. ${ }^{4}$ Otherwise, the transmission of the as grown sample was also measured and indicates a short cut-off wavelength of $0.49 \mu \mathrm{m}$ $(2.53 \mathrm{eV})$. Thus, the as-grown crystal cut-off is shifted to longer wavelengths due to absorption losses which clearly explain the crystal's orange color. Otherwise, the as-grown sample has sharp peak absorption at 2.9, 4 and $10 \mu \mathrm{m}$ which may be attributed to water contaminations (H-S and $-\mathrm{OH}$ bonds $)^{18} .^{2}$ These absorptions were eliminated by the annealing treatment (Figure 11).

The measured thermal conductivity value of as-grown sample was $0.40 \mathrm{~W} \cdot \mathrm{m}^{-1} \cdot \mathrm{K}^{-1}$ which is in good agreement with the $0.399 \pm 0.002 \mathrm{~W} \cdot \mathrm{m}^{-1} \cdot \mathrm{K}^{-1}$ value reported by Schunemann et 


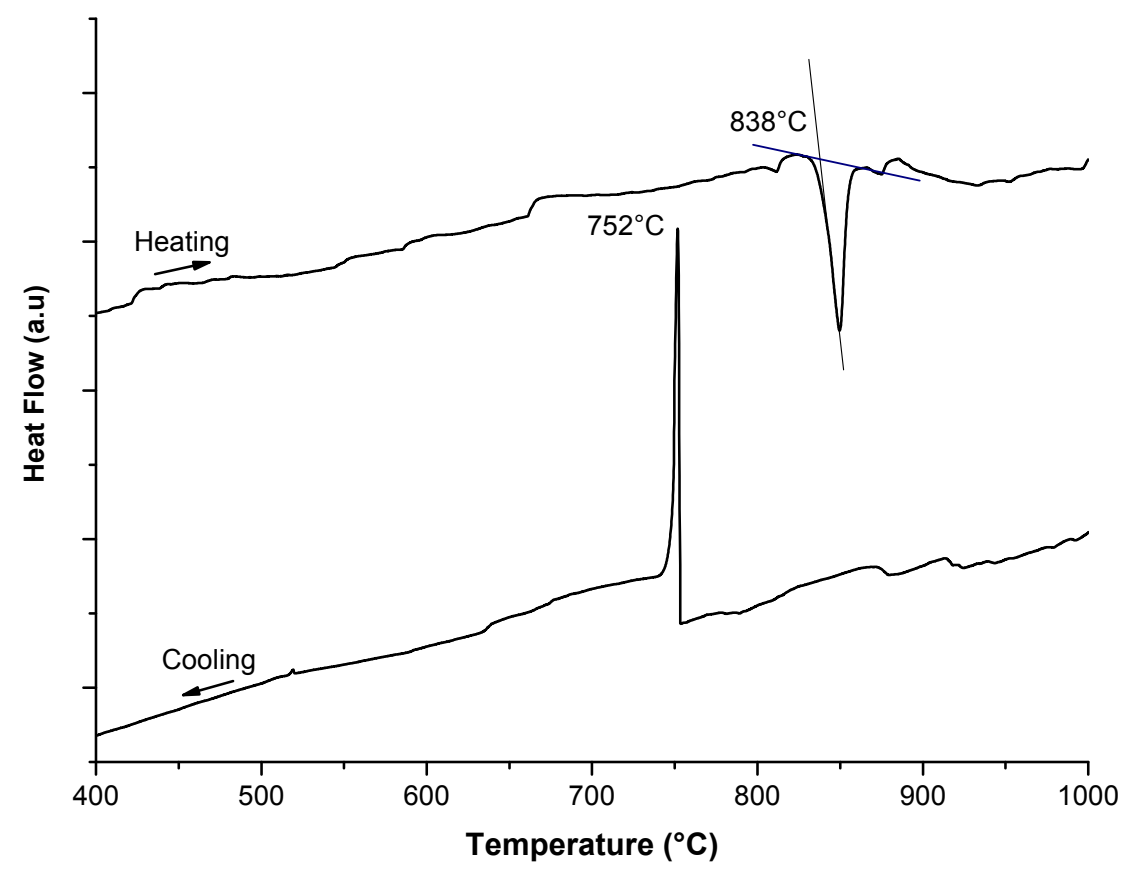

Figure 10: DTA analysis showing the melting and crystallization temperatures of $\mathrm{AgGeGeS}_{4}$.

al. ${ }^{2}$ Otherwise, we measured a thermal conductivity value on annealed sample $10 \%$ higher than in the as-grown sample which is is probably related to the decrease of crystal defect.

\section{Conclusions}

The strong influence of $\mathrm{GeS}_{2}$ vaporization on melt stoichiometry and crystal quality was outlined in this study. Solutions to reduce the impact of this compound's volatility on stoichiometry were presented. With optimized experimental conditions, we have synthesized high quality $\mathrm{AgGaGeS}_{4}$ polycrystals and then growth good optical quality single crystals by the Bridgman-Stockbarger method. These crystals have good homogeneity and the absorption loss coefficient was below $0.1 \mathrm{~cm}^{-1}$ in the $2-8 \mu \mathrm{m}$ spectral range which makes it suitable for non linear optical applications. DFG and SHG experiments are currently in progress in order to evaluate the performance of our crystals. We expect that this analysis can be helpful for the processing of such nonlinear infrared materials which may experience 


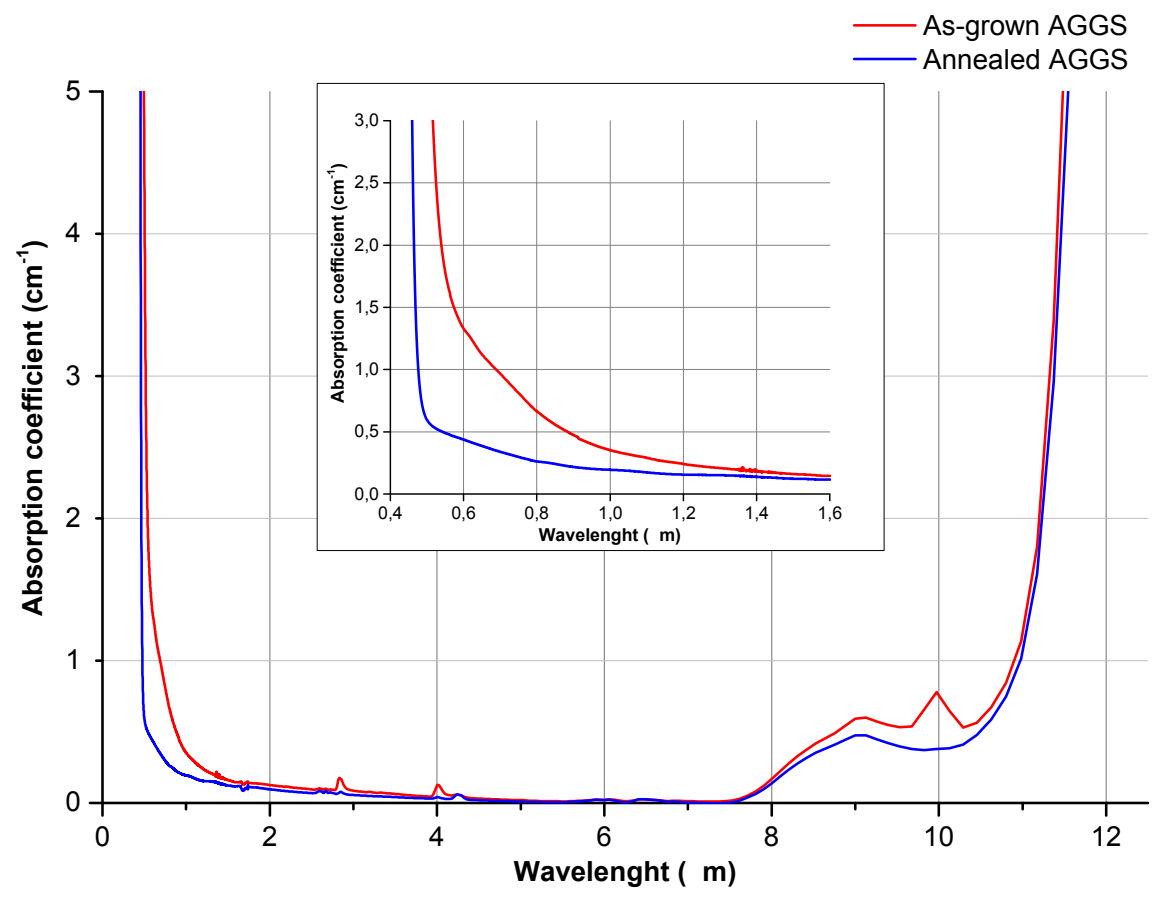

Figure 11: Optical absorption of AGGS sample (thickness: $4.4 \mathrm{~mm}$ ) in the $0.5-12.5 \mu \mathrm{m}$ range.

the same volatility problems.

\section{Acknowledgement}

The authors thank Loiseau P. from IRCP Chimie ParisTech for allowing us to collect X-ray data. We also want to thank Ritt M.H and Jankowiak A. from the Departement of composite materials of the ONERA for their guidances on DTA measurements.

\section{References}

(1) (a) Petit, J.; Godard, A.; Raybaut, M.; Melkonian, J.-M.; Lefebvre, M. Mid-IR nonlinear materials: chemical synthesis, crystal growth, and difference frequency generation in ZnGeP. 2010; pp 783811-783811-6; (b) Antoine, G. Comptes Rendus Physique 2007, 8, 1100-1128; (c) Petrov Valentin, Optical Materials 2012, 34, 536-554. 
(2) (a) Schunemann, P. G.; Zawilski, K. T.; Pollak, T. M. Journal of Crystal Growth 2006, 287, 248-251; (b) Petrov, V.; Badikov, V.; Panyutin, V. In Mid-Infrared Coherent Sources and Applications; Ebrahim-Zadeh, M., Sorokina, I. T., Eds.; Springer Netherlands: Dordrecht, 2008; pp 105-147.

(3) Pobedimskaya, E. Sov. Phys. Dokl. 1981, 26, 259.

(4) Badikov, V.; Tyulyupa, A.; Shevyrdyaeva, G.; Sheina, S. Inorg. Mater. 1991, 27, 177180.

(5) Andreev, Y.; Geiko, P. P.; Badikov, V. V.; Bhar, G. C.; Das, S.; Chaudhury, A. K. Nonlinear Optics (Mclc) Section B 2002, 29, 19-27.

(6) Petrov, V.; Badikov, V.; Shevyrdyaeva, G.; Panyutin, V.; Chizhikov, V. Optical Materials 2004, 26, 217-222.

(7) (a) De-Ming, R.; Jin-Zhe, H.; Yan-Chen, Q.; Xiao-Yong, H.; Yuri, A.; Pavel, G.; Valerii, B.; Anna, S. Chinese Physics 2004, 13, 1468-1473; (b) Badikov, V.; Shevyrdyaeva, G.; Chizhikov, V.; Panyutin, V.; Xu, G.; Petrov, V.; Noack, F. Applied Physics Letters 2005, 87, 241113-241113-3; (c) Miyata, K.; Petrov, V.; Kato, K. Appl. Optics 2007, 46, 6848-6848; (d) Ni, Y.; Wu, H.; Wang, Z.; Mao, M.; Cheng, G.; Fei, H. Journal of Crystal Growth 2009, 311, 1404-1406.

(8) Wu, H.; Ni, Y.; Lin, C.; Mao, M.; Cheng, G.; Wang, Z. Frontiers of Optoelectronics in China 2011, 4, 137-140.

(9) Chbani, N.; Loireau-Lozac'h, A.-M.; Rivet, J.; Dugue, J. Journal of Solid State Chemistry 1995, 117, 189-200.

(10) Olekseyuk, I.; Gorgut, G.; Shevtchuk, M. Pol. J. Chem. 2002, 76, 915-919, WOS:000176390600002.

(11) Petit, J.; Bejet, M.; Daux, J.-C. Materials Chemistry and Physics 2010, 119, 1-3. 
(12) Das, S.; Ghosh, C.; Gangopadhyay, S.; Andreev, Y. M.; Badikov, V. V. Japanese Journal of Applied Physics 2006, 45, 5795-5797.

(13) Vasilyeva, I. G.; Nikolaev, R. E. Inorganic Materials 2006, 42, 1299-1301.

(14) (a) Zawilski, K. T.; Schunemann, P. G.; Setzler, S. D.; Pollak, T. M. Journal of Crystal Growth 2008, 310, 1891-1896; (b) Verozubova, G.; Okunev, A.; Gribenyukov, A.; Trofimiv, A.; Trukhanov, E.; Kolesnikov, A. Journal of Crystal Growth 2010, 312, 1122-1126; (c) Lei, Z.; Zhu, C.; Xu, C.; Yao, B.; Yang, C. Journal of Crystal Growth 2014, 389, 23-29.

(15) Chen, B.; Zhu, S.; Zhao, B.; Lei, Y.; Wu, X.; Yuan, Z.; He, Z. Journal of Crystal Growth 2008, 310, 635-638.

(16) Nikolaev, R.; Vasilyeva, I. Journal of Solid State Chemistry 2013, 203, 340-344.

(17) Lucas, E. M. D.; Canat, G.; Lombard, L.; Jaouën, Y.; Bordais, S. Pulsed kW-peak power and integrated all fiber MOPA single-frequency source at 2050nm. 2014; pp 91350M-91350M-7.

(18) Young, P. A. Journal of Physics C: Solid State Physics 1971, 4, 93-106. 


\section{Graphical TOC Entry}

$\mathrm{AgGaGeS}_{4}$ (AGGS) is a promising nonlinear crystal for mid-IR laser applications. The chemical synthesis and the single crystal growth process of this material are presented. Single crystals with $28 \mathrm{~mm}$ diameter and $70 \mathrm{~mm}$ length were grown by the Bridgman-Stockbarger method. The influence of $\mathrm{GeS}_{2}$ volatility on melt stoichiometry during the $\mathrm{AgGaGeS}_{4}$ processing was studied in order to

mprove the quality of grown crystals.

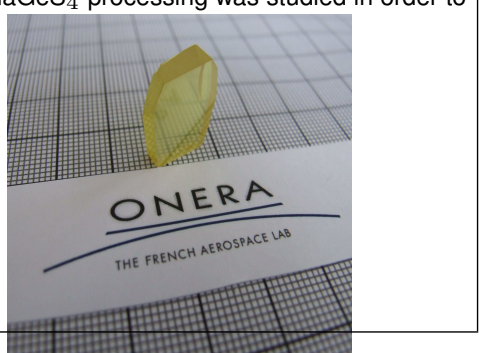

